\section{MS30-P5 Comparison of hydrates of 4,6-diaminopyrimidine with selected dicarboxylic acids (oxalic, malonic, succinic, glutaric and adipic)}

Jan Fábry ${ }^{1}$, Irena Matulkováª , Jana Mathauserová ${ }^{2}$ Ivan Němec ${ }^{2}$, Ivana Císařová ${ }^{2}$

1. Institute of Physics, Academy of Sciences of the Czech Republic, Na Slovance 2, 18221 Praha 8, Czech Republic, E-mail: fabry@fzu.cz

2. Faculty of Science, Department of Inorganic Chemistry, Charles University in Prague, Hlavova 2030/8, 12843 Praha 2, Czech Republic

email: fabry@fzu.cz

The structures of $2\left(\mathrm{C}_{4} \mathrm{~N}_{4} \mathrm{H}_{7}^{+}\right) \cdot \mathrm{C}_{2} \mathrm{O}_{4}{ }^{2-} \cdot 4 \mathrm{H}_{2} \mathrm{O}$; $\mathrm{C}_{4} \mathrm{~N}_{4} \mathrm{H}_{7}^{+} \cdot \mathrm{C}_{3} \mathrm{H}_{3} \mathrm{O}_{4}^{-} \cdot \mathrm{H}_{2} \mathrm{O} ; 2\left(\mathrm{C}_{4} \mathrm{~N}_{4} \mathrm{H}_{7}^{+4}\right) \cdot \mathrm{C}_{4} \mathrm{H}_{4} \mathrm{O}_{4}{ }^{24} \cdot 8 \mathrm{H}_{2}^{2} \mathrm{O}$ $2\left(\mathrm{C}_{4}^{4} \mathrm{~N}_{4}^{7} \mathrm{H}_{7}^{+}\right) \cdot \mathrm{C}_{5} \mathrm{H}_{6} \mathrm{O}_{4}^{2-} \cdot 2 \mathrm{H}_{2} \mathrm{O}{ }_{4}{ }_{7} \mathrm{C}_{4} \mathrm{H}_{4} \mathrm{O}_{4}$ and $\left.2\left(\mathrm{C}_{4} \mathrm{~N}_{4} \mathrm{H}_{7}^{4}\right) \cdot \mathrm{C}_{6} \mathrm{H}_{8} \mathrm{O}_{4}^{4-} \cdot 8 \mathrm{H}_{2} \mathrm{O}\right)$ are compared. There are common features in the title structures: 1] All of them are centrosymmetric. The molecules of ethanedioic, butanedioic and hexanedioic acid are situated on the inversion centres. 2] In all the structures, there are $\mathrm{N}-\mathrm{H} . . \mathrm{N}, \mathrm{N}-\mathrm{H} . . . \mathrm{O}_{\text {,id }}$, N-H...Ow and $\mathrm{Ow}-\mathrm{H} . . . \mathrm{O}$ and Ow-H...Ow hydrogen bonds. The intermolecular hydrogen bonds are of moderate strength. 3] There are graph set motifs $R^{2}{ }_{2}(8)$ in which the dicarboxylic groups and the primary and secondary amine groups are involved. The secondary amine group tends to form a somewhat shorter hydrogen bond with respect to the primary amine group. 4] There is a growing complexity of arrangement of the water molecules towards the structures with a longer dicarboxylic molecule while it seems that the dependence on the parity of the number of carbon atoms in the dicarboxylic acid is present: in the structure with ethanedioic acid the water molecules form rows parallel to $\mathrm{b}$ axis; in the structure with hydrogen propanedioic acid the water molecules are linked in a pair of water molecules; in the structure with butanedioic acid the water molecules themselves form layers composed of annelated six-membered rings parallel to $\left(\begin{array}{lll}0 & 1 & 0\end{array}\right)$; in the structure with pentanedioic acid the water molecules themselves forms rows along b axis; in the structure with hexanedioic acid the water molecules themselves form columns parallel to $\mathrm{b}$ axis while each layer in the column contains 4 water molecules. This substructure corresponds to a section from structure of pure water though the hydrogens are ordered in the title structure.

\section{Acknowledgements:}

This work was supported by the Czech Science Foundation (grant no. 14-05506S).

Keywords: hydrogen bonding, dicarboxylic acids, 4,6-diaminopyrimidine

\section{MS30-P6 Crystal Engineering: From Form to Function}

Michael Zaworotko ${ }^{1}$

\section{University of Limerick}

email: Michael.Zaworotko@ul.ie

That composition and structure profoundly impact the properties of crystalline solids has provided impetus for exponential growth in the field of crystal engineering ${ }^{1}$ over the past 25 years. This lecture will address how crystal engineering has evolved from structure design (form) to control over bulk properties (function).

Strategies for the generation of two classes of functional crystalline materials will be addressed:

Multicomponent pharmaceutical materials, MPMs, such as cocrystals ${ }^{2}$ have emerged at the preformulation stage of drug development. This results from their modular and designable nature which facilitates the discovery of new crystal forms of active pharmaceutical ingredients, APIs, with changed physicochemical properties. The concept of "ionic cocrystals" will be explained and a case study addressing brain bioavailability of lithium will be presented.

Hybrid Ultramicroporous Materials, HUMs, are built from metal or metal cluster "nodes" and combinations of organic and inorganic "linkers". Two families of HUMs that afford exceptional control over pore chemistry, pore size and binding energy, will be detailed. Benchmark selectivity for $\mathrm{CO}_{2}$ capture in these HUMs with pcu or mmo (see Figure) topology has been observed ${ }^{3}$ thanks to the strong electrostatics associated with pores lined by the inorganic components of these nets. New results that address other applications of HUMs will be presented and discussed.

1. (a) Desiraju, G.R. Crystal engineering: The design of organic solids Elsevier, 1989; (b) Moulton, B.; Zaworotko, M.J. Chemical Reviews 2001, 101, 1629-1658.

2. Duggirala, N.; Perry, M.L.; Almarsson, Ö.; Zaworotko, M.J. Chem. Commun. 52, 640-655, 2016.

3. Nugent, P.; Belmabkhout, Y.; Burd, S.D.; Cairns, A.J.; Luebke, R.; Forrest, K.; Pham, T.; Ma, S.; Space, B.; Wojtas, L.; Eddaoudi, M.; Zaworotko, M.J. Nature 2013, 495, 80-84, 2013.

Keywords: crystal engineering 